\title{
The impact of gout on patient's lives: a study of African-American and Caucasian men and women with gout
}

\author{
Jasvinder A Singh ${ }^{1,2,3}$
}

\begin{abstract}
Introduction: The aim of this study was to examine the impact of gout on quality of life (QOL) and study differences by gender and race.

Methods: Ten race- and sex-stratified nominal groups were conducted, oversampling for African-Americans and women with gout. Patients presented, discussed, combined and rank-ordered their concerns.

Results: A total of 62 patients with mean age 65.1 years, 60\% men, 64\% African-American, participated in 10 nominal groups: African-American men ( $n=23 ; 3$ groups); African-American women ( $n=18 ; 3$ groups); Caucasian men ( $n=15$; 3 groups); and Caucasian women ( $n=6 ; 1$ group). The most frequently cited high-ranked concerns among the ten nominal groups were: (1) effect of gout flare on daily activities ( $n=10$ groups); ( 2 ) work disability ( $n=8$ groups); (3) severe pain ( $n=8$ groups); (4) joint swelling and tenderness ( $n=6$ groups); (5) food restrictions ( $n=6$ groups); (6) medication related issues ( $n=6$ groups); (7) dependency on family and others ( $n=5$ groups); ( 8 ) emotional Impact ( $\mathrm{n}=5$ groups); (9) interference with sexual function ( $\mathrm{n}=4$ groups); (10) difficulty with shoes ( $\mathrm{n}=4$ groups); and (11) sleep disruption ( $n=4$ groups). Compared with men, women ranked the following concerns high more often: problems with shoes ( $n=4$ versus $n=0$ groups); dependency ( $n=3$ versus $n=2$ groups); and joint/limb deformity ( $n=2$ versus $n=0$ group). Compared with Caucasians, African-Americans ranked the following concerns high more often: dietary restrictions ( $n=6$ versus $n=0$ groups); severe pain ( $n=6$ versus $n=2$ groups); gout bringing the day to a "halt" ( $n=2$ versus $n=0$ group); effect on emotional health ( $n=4$ versus $n=1$ groups); and the need for canes/ crutches during flares ( $n=2$ versus $n=0$ group).
\end{abstract}

Conclusions: Gout has a significant impact on a patient's QOL. Important differences in the impact of gout by gender and race were noted.

\section{Introduction}

Gout is the most common type of inflammatory arthritis in adults. Gout affects 8.3 million Americans [1] and 5\% of the US veterans [2]. It leads to frequent emergency room visits [3] and costs 20 billion dollars annually [4]. Despite the availability of effective treatments, patients with gout do not receive good-quality gout care [2,5-10] as recommended by gout treatment guidelines [11,12].

\footnotetext{
Correspondence: Jasvinder.md@gmail.com

${ }^{1}$ Medicine Service, Birmingham VA Medical Center, Birmingham, AL, UK

${ }^{2}$ Department of Medicine at School of Medicine and Division of Epidemiology at School of Public Health, University of Alabama, Faculty Office Tower 805B, 510 20th Street S, Birmingham, AL 35294, UK

Full list of author information is available at the end of the article
}

Quality gaps are worse in racial minorities and women [13]. Significantly lower rates of urate-lowering therapy (ULT) prescriptions and ULT adherence are seen in African Americans $[14,15]$ compared to Caucasians and in women compared to men $[7,16]$. Patient perceptions can impact gout outcomes. An example is that negative or pessimistic patient views about gout are associated with poorly controlled gout, low adherence to ULT and higher disability [17]. This implies that better insights into patient experience and perception of gout are needed, especially in African Americans.

Gout has a significant negative effect on patient's quality of life (QOL) [18-21] and effective treatment improves QOL $[22,23]$. Therefore, it is critical to understand the 
specific impact of gout on patients' lives. To date, qualitative research in gout has focused on examining patients' knowledge related to gout, patterns of treatment and the barriers to treatment adherence [24-26]. There are at least three knowledge gaps related to the effect of gout on QOL: (1) qualitative studies have been done primarily in Caucasian men with gout; none included African Americans [24-26]; (2) only 11 of the 46 gout patients in all previous studies combined were women $[24,25]$, indicating the need for more research into women with gout; and (3) most studies have assessed multiple aspects of gout, including treatment, knowledge, disease monitoring, outcomes and patient and clinician perspective, often in a setting of a single study [24-26]. Thus, there is a lack of in-depth studies assessing the impact of gout on QOL.

The lack of research in African Americans with gout, a racial group with higher disease prevalence and burden of gout than Caucasians ( $5 \%$ versus $4 \%$ in the US), is concerning [1]. Although gout is not as common as it is in men, the prevalence is $2 \%$ in US adult women [1], twice that of rheumatoid arthritis at 1\% [27]. A literature search using the same terms (quality of life, women) found eight publications in gout (none with original data, none relevant) versus 213 publications in rheumatoid arthritis, indicating the lack of recognition of the impact of gout on women.

Corbin and Strauss proposed the trajectory model to understand the impact of illness further refined by Charmaz and others. The model includes three components - body, biographical time (explicit narrative that gives meaning and purpose to a person's life) and conceptions of self (constructs of self-image and identity, such as role identity, social identity et cetera), that is, the $\mathrm{BBC}$ chain $[28,29]$. The model indicates that only when body, biographical time, and conceptions of self are in balance, interactively stabilizing and reinforcing one another, does one enjoy a sense of health and wellbeing [28-30]. When this chain is destabilized, one has the sense of being ill. A chronic disease may lead to progressive loss of self from body failures, failed performances and social isolation [31]. The study question is based on this theoretical model and the study findings were mapped to this model. The objectives of this study were to: 1) assess the impact of gout on patients' QOL; and (2) explore gender and race differences in the impact of gout on patients' QOL. We oversampled for African Americans and women to get a diverse perspective.

\section{Methods}

\section{Patients}

The Institutional Review Board at the University of Alabama at Birmingham approved the study. Patients with at least one outpatient visit between January 2011 to
September 2012 to our outpatient clinic, with an International Classification of Diseases, ninth revision, common modification (ICD-9-CM) code for gout, that is, 274.xx, were eligible and invited for study participation on the phone. Consecutive patients were selected. African Americans and women were oversampled, due to the lack of qualitative research in these groups. Patients were invited for 1.0 to 1.5 hour sessions. Study participants received free parking, refreshments during the session and a $\$ 30$ check. Patients provided consent prior to study initiation.

\section{Nominal group technique (NGT) sessions and analyses}

Patient nominal groups were conducted to understand the impact of gout on the patient's QOL and evaluate gender and racial differences. NGT is a variant on traditional focus group with methods aimed at developing an inclusive list of issues related to a specific question, then soliciting feedback on the relative importance of these lists through rank-ordering procedures [32,33]. NGT has been used successfully in a variety of medical conditions with assessments from experts, professional caregivers and patient groups [33-39]. NGT taps the experiences, skills, or feelings of the participants by promoting an even participation. Thus, the data generated usually provide a more valid representation of the implicit views of the group than would be achieved with a focus group format. Generally, two to three groups are considered enough to reach saturation.

Given that QOL is not a lay-person concept, careful consideration was given as to how to ask the question about how gout affects patients' QOL. After several discussions with pyschometricians, physicians, and patients with gout in the clinical practice, the question was finalized as, 'How does gout affect your life?' The nominal groups were stratified by gender and race/ethnicity. The nominal group leader (JAS), an epidemiologist experienced in conducting nominal groups [40,41], conducted the nominal group sessions. Research assistants (BA, AO or $A B$ ), provided administrative support, recorded the discussions and took notes. Each session started with introductions followed by asking the participants if the main question was clear and if they had any questions prior to starting the group meeting. All queries were answered before the start of each NGT session. The main question was written on flipchart and also printed on top of a blank sheet of paper provided to each participant.

The NGT process consisted of the following discrete steps that were completed in 60 to 70 minutes, as planned: (1) participants briefly and independently generated as many words or short phrases as possible in response to the question on a sheet of paper with the question (10 to 15 minutes); (2) participants nominated a single response in a round-robin fashion, which was recorded on a flip 
chart in large letters visible to the group participants by the group leader; responses are nominated until all identified by any group member were recorded; (3) once the list was completed, participants discussed and elaborated each response and where appropriate combined responses deemed alike; and (4) all participants were asked to identify and rank-order the five responses deemed most important from 1 to 5 , with 5 being the highest score on the index cards. All scores were totaled. A rank-order was created based on the total scores, with the highest score corresponding to the top rank.

Rank-ordered results from each nominal group were created. Similar to the within-group process, responses were analyzed based on the number of nominal groups identifying the concept with high relative rank-ordering. A general consensus rank-ordered list was created. Transcriptions were examined to identify all statements made relative to each response (discussions directly connected, solutions generated, and any point where the response was brought up subsequently) and led to the creation of a comprehensive list of statements. To ensure that nominal groups were performed until saturation, as groups were completed, responses were compared to determine overlap. When significant overlap was noted, saturation was confirmed.

\section{Results}

Ten nominal groups were conducted with 62 gout patients: 60\% were men and 40\% women, 64\% African American and 36\% Caucasian. The mean age was 65.1 years (standard deviation, 10.8). Three nominal groups each were conducted with African American men, African American women, and Caucasian men and one nominal group with Caucasian women. Saturation of themes was achieved by the third group in each group. The mean age (standard deviation) of the four cohorts that participated in nominal groups were: African American men, 61.8 (12.4); African American women, 68.9 (10.4); Caucasian men, 63.8 (12.6); and Caucasian women, 61.3 (2.3).

\section{Overall impact of gout on quality of life}

Several themes emerged. The top seven (or so) themes/ concerns from each group are listed in Tables 1 and 2 . In the section below, we list the top seven concerns nominated by more than one nominal group. These concerns are categorized as identity-relevant performances with or without loss of self versus body failures, although some themes may fall into more than one category.

The top concerns/domains noted by the patients were mapped to the limitation of identity-relevant performances with a progressive loss of self, exemplified by the following themes.

\section{Effect of gout flare on daily activities and the ability to do things}

All ten groups listed this among their top concerns. Gout affected: (1) activities of daily living: walking, getting out of bed, going to bathroom, standing, climbing stairs, combing hair, cooking; (2) other instrumental activities: driving, writing, gardening, cleaning dishes; (3) the ability to take care of family; and (4) social activities such as going to church, traveling, going out of town.

\section{Effect on work ability, and productivity and employability and at home productivity}

Eight patient groups listed this among their top concerns. The ability to function normally at work, work productivity and relationships were affected. Several patients lost employment due to gout. Women reported decreased productivity at home and interference with their ability to take care of their families and the house.

\section{Severe pain during a gout attack and its impact on physical and emotional health}

This was among the top concerns in eight nominal groups. Patients had problem with physical (inability to get out of bed) and emotional health (crying due to pain) and systemic effects of severe gout pain such as the loss of appetite due to pain. All eight groups described the impact of gout on physical health. Five groups (four African American and one Caucasian) highlighted the impact of gout on emotional health.

\section{Dependency on family and others}

Five patient groups listed this among their top concerns. Patients reported needing help from family members during gout flares for household work (for example, with cooking), ambulation and for getting to the doctor's office.

\section{Difficulty with shoes}

Four patient groups expressed difficulty in wearing shoes, going to church with home shoes on and the need to wear a wider shoe, shoes of a larger size or walk barefoot sometimes. Some patients had to stop wearing fancy shoes and heels.

\section{Interference with sexual function}

Four patient groups listed this among their top concerns (all male nominal groups). Patients described that gout flares affected their sexual function negatively, leading to problems in having sex as well as low/no desire to have sex, and gout affecting their marital relationship negatively. 
Table 1 Top ranked seven concerns* among African American and Caucasian men

\section{Quotes}

African American men $(n=5)$

Impact of flare on social life

Pain during and after the flare and its impact

Limitation of recreational activities

Work productivity

Unpredictability of flare that brings a normal day to a halt

Dietary restrictions and modification

Feeling of loss of youth

African American men $(n=9)$

Severe pain and disability during an attack

Swelling and tenderness in acute flare

Affects sleep

Dietary restrictions and modification

Need for daily medication
'Affects my social life - Going to dinner, church, movies, etc'

'I don't want to be around anybody during the attack'

'...(flare causes)...extreme pain'

'Crying while I am in pain'

'It makes me emotional and mean when I have an attack'

'Things that I like are taken away (music)'

'I can't go (places...) with my brothers'

'Affects my hobbies - fishing, hunting, biking, playing music, riding motorcycle, running'

'Hopefully your boss understands'

'Relationships are hard at work too'

'Caused me to take off from (or ability to do) my job.'

'Brings normal day to a halt'

'Stopping the desire to do anything'

'Comes unexpected'

'Don't even want someone breathing around me'

'What do different foods contribute to gout?'

'Staying away from fish, shellfish, steaks, \& peas'

'Affects foods I can enjoy'

'Always have to watch what I eat - staying disciplined'

II was diagnosed in my 20s... feel old...

'Causes me to feel "old" before my time'

When I have an attack it shuts down my whole life. I can't function. I will stay in the bed three to four days while I wait for it to pass'

'Have to have wheel chair close to me during an attack'

'I have to keep my crutches by the bed so that I can get to the bathroom'

'You will do anything to get relief'

'I miss going to church and other functions'

'My toe ankle and knee they really swell up.'

'...tenderness in the acute phase'

'Limits my ability to have a good night sleep'

'You just can't sleep'

'Affects what I can eat'

'Can't have a few drinks without a flare'

'Can't eat red meat, even though I love it'

'... have got to take medication every day'

'It's inconvenient'

'It's just another drug when you add that to our other medications'

'I also have to take a pain medication' 


\section{Table 1 Top ranked seven concerns* among African American and Caucasian men (Continued)}

At-home productivity and dependency on family members and others

Affect on family life and sexual function

African-American men $(n=9)$

Dietary restrictions and modification

Problem with daily activities

Sexual difficulties

Problem with shoes/footwear

Joint swelling
'It disables me. I need help with my socks or just walking around the house'

'I can't use lawn mower'

'Need help from family and others'

'During a flare up I need help just to get me to the doctor'

'One time the fire department had to find a way to get me out of the bed, into a wheelchair, into the back of a truck then to the hospital... It took a whole lot of help to get to the doctor that day'

'I can't do anything someone will have to bring me food, help me in and out of the bed; hop to the bathroom during an attack'

'I can't go to my grandson's game'

'I can't do the things I like to do with my wife'

'My relationships are affected... I don't want anyone around me to touch me'

'Made me change my diet'

'I had to change the food that I ate'

'I can't eat seasoned food; I did not like that at all'

'No seafood, shell fish, red meat and fried foods'

'Watch what you drink - no alcohol'

'Can't have sodas or drink orange juice'

'Can't have peanuts, pecans and tomatoes'

'Hard to move around'

Very hard to move around during a flare. It stays with me for a while, several days'

'Could not stand and it would hurt if the cover was touching it'

'Have to be careful what you can do'

'No activity outside'

'It's aggravating, not being able to do anything'

'All you want is the pain to go away'

'Gout affects my driving'

'During the flare there is a problem going to the restroom'

'I couldn't drive my truck if my gout was flaring. I had to learn to shift with my left foot. My diet, activities and everything had to change because I could not do it like I used to'

'Problem with having sex during the flare. When you are in pain... the love goes'

'You don't want to do anything when you are in pain. Our old lady doesn't understand'

'I wore a wider shoe'

'I had to get shoes 2 sizes larger'

'Needed hard leather shoes and loose fitting shoes'

'Get out of the fancy shoes and wear some soft shoes'

'I wear sandals'

'Affects my joints - I have swelling' 


\section{Table 1 Top ranked seven concerns* among African American and Caucasian men (Continued)}

\begin{tabular}{|c|c|c|}
\hline \multirow[t]{3}{*}{ Life-changing impact } & 'Made my life change in a lot of ways' & 9 \\
\hline & $\begin{array}{l}\text { 'My whole life changed. I had to accept a lot of things that I did } \\
\text { not want to' }\end{array}$ & \\
\hline & $\begin{array}{l}\text { 'Pain made me change in a lot of ways with my friends family and } \\
\text { the people that I am normally around. It will have an impact on } \\
\text { the way your carry yourself' }\end{array}$ & \\
\hline \multirow[t]{4}{*}{ Severe pain during flare } & 'Can't have anything touching it a sheet, clothes... nothing.' & 9 \\
\hline & '...when it flares up you can't sleep' & \\
\hline & 'I have to sleep a certain way to avoid pain' & \\
\hline & 'I have to sleep in a chair' & \\
\hline \multirow[t]{2}{*}{ Emotional impact } & 'Can't play with pain' & 7 \\
\hline & 'Makes me irritated' & \\
\hline \multicolumn{3}{|l|}{ Caucasian men $(n=5)$} \\
\hline \multirow[t]{6}{*}{ Problem with daily activities and at-home productivity } & 'Gout affects my physical abilities' & 17 \\
\hline & $\begin{array}{l}\text { 'I can't garden or do yard work anymore. Can't do vegetable } \\
\text { gardening' }\end{array}$ & \\
\hline & $\begin{array}{l}\text { 'Work around the house is impossible when I have a harsh gout } \\
\text { attack' }\end{array}$ & \\
\hline & '...(during flare)... My sink is full of dishes' & \\
\hline & 'Standing is a devil (during flare).' & \\
\hline & $\begin{array}{l}\text { 'My inability to walk and move around totally limits my life (to go } \\
\text { to the bathroom, eat do anything)' }\end{array}$ & \\
\hline \multirow[t]{2}{*}{ Impact on family life and sexual function } & 'Affects your sex life' & 10 \\
\hline & 'My life with family has suffered' & \\
\hline \multirow[t]{4}{*}{ Work productivity } & 'My work output suffers' & 8 \\
\hline & $\begin{array}{l}\text { 'I get paid on commission. My average has dropped over the years } \\
\text { due to gout' }\end{array}$ & \\
\hline & 'Affects my job. A limitation to the job' & \\
\hline & 'The medication (narcotics) has made it difficult to work' & \\
\hline \multirow[t]{5}{*}{ Long-term medication side-effects } & $\begin{array}{l}\text { 'Affects your personality usually due to the medication that you } \\
\text { are taking (steroids)' }\end{array}$ & 7 \\
\hline & 'I worry about the long term affects the drugs have on my health' & \\
\hline & $\begin{array}{l}\text { 'The side affects that I have or could get from the medication or } \\
\text { the disease' }\end{array}$ & \\
\hline & $\begin{array}{l}\text { 'My joints are deteriorated due to me continuing to move during } \\
\text { a flare up' }\end{array}$ & \\
\hline & $\begin{array}{l}\text { "Because I have one kidney my pain reliving drugs are even more } \\
\text { limited" }\end{array}$ & \\
\hline \multirow[t]{3}{*}{ Impact on comorbidity management } & 'How it (gout) interacts with my other health issues' & 6 \\
\hline & 'Raises blood pressure' & \\
\hline & $\begin{array}{l}\text { 'That's my problem - I do not know how it is affecting my other } \\
\text { problems. I ask my doctor all the time' }\end{array}$ & \\
\hline \multirow[t]{3}{*}{ Dependency on family members } & $\begin{array}{l}\text { 'I don't like to be waited on... they should not have to bear that } \\
\text { burden' }\end{array}$ & 5 \\
\hline & 'I have to have help when I am having a severe attack' & \\
\hline & $\begin{array}{l}\text { 'Concern over being dependent on my wife and family because of } \\
\text { my limitations' }\end{array}$ & \\
\hline
\end{tabular}


Table 1 Top ranked seven concerns* among African American and Caucasian men (Continued)

Caucasian men $(n=7)$

Intense pain

Gout stops certain activities

Not predictable

Need for daily medication

Expenses of medications and doctor visits

Lack of healthiness

Possible drug interactions

Caucasian men $(n=3)$

Severe pain

Physical limitation

Emotional impact
'Gout leads to severe pain'

'Attack in the unusual places'

'Unable to live the active life tat I live'

'Limited movement'

'....couldn't walk'

'Inability to exercise, have family interactions'

'..(had to) reduce daily activities'

'Limitation of mobility'

'Don't you wish you knew'

'Can not plan activities in town and out of town'

'Out of town, can not get medical attention quick for an attack'

'Take medication everyday and buy it'

'If you travel you are stuck with them'

'...(problem) having to take daily medications'

I have group health insurance and my condition has impact on others'

'Limitation of disposable income'

'....emergency room visits are expensive'

'....contributes to the sense of lack of healthiness'

'Lot of unexplained symptoms, wondering if they might be due to side effects of allopurinol'

'We are getting older and need to worry about these'

'What about it's effect on medications for other diseases'

'Pain was so much, I could hardly walk'

'I broke my leg an year ago, I swear gout hurt worse than my fracture'

'I broke my ankle, not even comparable to acute gout attack (gout was worse)'

'Pain from gout was worse than neck fusion symptoms'

'I can feel the pain with every heartbeat'

'Limits my ability to play sports, family events and excursions, vacation, home improvement and chores'

'Limits sporting events during the attack'

'Could hike, if it weren't there'

'Has long-term impact on hobbies'

'I had to give up sports I played my whole life'

'Had to so "no" a lot'

'Had an attack during vacation. I couldn't do things and make me think of polio'

'Puts emotional strain in relationships, marriage and family'

7

'People have heard about it, but don't know what it is'

'It led to my divorce'

My wife said in her journal "... seems that he wants to be in pain to avoid doing things with me'

'My family and wife know very well what gout is' 
Table 1 Top ranked seven concerns* among African American and Caucasian men (Continued)

\begin{tabular}{|c|c|c|}
\hline \multirow[t]{5}{*}{ Limits work ability } & 'Limits my ability to work' & 6 \\
\hline & 'Delay, reschedule or ask coworkers (ask for help)' & \\
\hline & 'Traveling is difficult' & \\
\hline & 'Can't drive' & \\
\hline & '....had to get cherry juice and spend a night in a hotel' & \\
\hline \multirow[t]{4}{*}{ Need to take daily medication } & 'Have to take medication daily' & 4 \\
\hline & 'Not easy to fill and refill, especially when traveling' & \\
\hline & 'I don't like taking medications every day' & \\
\hline & 'Allopurinol if a miracle drug' & \\
\hline \multirow[t]{2}{*}{ Awareness of joint disease } & 'Constantly cautious of joint sensitivity' & 4 \\
\hline & 'Anytime I feel something it constantly reminds me of my attacks' & \\
\hline \multirow[t]{3}{*}{ Finding fellow people with gout } & 'Bond with people who know how it feels' & 1 \\
\hline & 'Becoming part of social interaction' & \\
\hline & 'Every friend of mine knows I have gout' & \\
\hline
\end{tabular}

*Since some concerns were ranked equally by a group and tied for a rank, some groups have more than seven concerns.

\section{Sleep disruptions}

Four patient groups reported sleep problems due to gout, both an altered sleep pattern in general due to gout and severe disruptive effect of gout flares on sleep.

\section{Bringing normal day to a halt and unpredictability}

Two groups ranked this among their top concerns. Patients mentioned the need to stop doing everything when the flare hit. Unpredictability of gout flare was very concerning to patients. Patients said that gout flare ruined their plans and they were uncomfortable with the unpredictable aspect of gout flares.

\section{Made life change in a lot of ways}

One patient group pointed out that their life changed in a lot of ways due to gout. Another patient group highlighted that gout led to the lack of healthiness. One patient had a divorce due to his inability to do outdoor activities with his wife due to frequent gout flares. Patients had to accept a lot of things that they did not want to, and the experience with gout '...made them change the way they carried themselves out.'

\section{Effect on hobbies and social life}

One patient group said that gout affected not only their ability to continue their hobbies including fishing, hunting, biking, riding motorcycles, playing music and running, but also with the ability to go to dinner, movies and church.

\section{Seeking people like them in social circles}

One patient group described that gout was shaping their social and work interactions and that it was becoming an integral part of their social interactions. Patients were seeking others with similar conditions and bonding with them.

Other concerns and domains were consistent with body failure, as described in the trajectory model, as noted below.

\section{Joint swelling, tenderness, heat and stiffness}

Six groups listed this among their top concerns. Patients reported joint swelling, heat and tenderness during flares, residual joint swelling after the flare and joint stiffness.

\section{Food restrictions}

Six groups listed this among their top concerns. Patients reported having to give up foods that they enjoyed (red meat, shellfish, seafood), the need to stay disciplined with food and alcohol, the uncertainty about exactly which foods to avoid and the discomfort with dietary changes that they had made and the fear of (specific) food items causing flaring-up of gout.

\section{Medication-related issues}

Six patient groups listed this among their top concerns. Patients reported the inconvenience of taking pills daily, the need for multiple medications, the side effects from medications and the concern of potential long-term side effects. In one group, three of the top seven concerns were related to the negative impact of medications on QOL.

\section{Impact on other health conditions}

Two patient groups were concerned about the impact of gout on their other health conditions, including hypertension, conflicting messages from doctors and their concern for drug-drug interactions. 
Table 2 Top ranked seven concerns* for African-American and Caucasian women

African-American women $(n=3)$

Constant pain

Interactions with other medications

Concern and confusion regarding dietary restrictions

Joint swelling with discomfort and deformity

Severe pain

Concern about taking too many pills

Problem with daily activities, at-home productivity and dependency on family during gout flares

African-American women $(\mathrm{n}=8)$

Extreme pain
'Having to continue day to day tasks even with constant pain'

'I have high blood pressure and my gout medication would raise my blood pressure. The same issue with my diabetes medication'

'Medical doctors say don't take something that the rheumatologist said would help my gout because it would mess up other things'

'You get different lists when you Google this question. It says that everyone has to find what starts the attack for them'

'Red meat and some fish...' Any fish?'. ...(avoid) Dark green leafy vegetables.'

'I don't notice food'

'Unsure of what and what not to eat'

This is a social aspect because I get self conscious because my feet are so swollen.'

'Residual swelling in joints constantly in feet, unable to wear my shoes'

'My hand swells. I can't put my rings on some mornings'

'Supposed to have a brace on my hand for the swelling. I may have to have surgery on the hand'

'(Swelling)... on top of my foot or my big toe'

'Swelling in my shins and everywhere!!!'

'As soon as you take your foot of the bed'

'Can't even have the cover touching my feet.'

'Can even just lay there and still have pain'

'I am taking more pills than I would like to take to get rid of the pain and get any kind of sleep'

'When I have an attack, I can't walk; can't take care of my family, my home or myself'

'I can't get to bathroom, cook wash, or go to the store'

'I didn't care if anything was done because the pain was so severe. I also didn't know what it was. I couldn't walk they thought it could be a stress fracture until the blood work was reviewed. You are so concerned with pain you can't do anything. I would literally scream every time I would put my feet down. The first attack was in my shoulder I could not move it. I was given morphine and it was still hurting

'The prednisone makes me hold fluid. I have asked to be taken off of it; leaving me taking medicine I would not like to take'

'Can't walk it's so painful; I have to use crutches hop on one leg or crawl'

'During an extreme onset unable to walk at all'

'Can't clean the house'

'Family can't take care of my grandchildren properly. I have an ADHD child I have to keep up with'

'Hurts when I lay on my side at night'
'Sleepless nights when I get an attack'

'It's in my foot - it's hard to walk - I can't put on any shoes or touch it like a sheet or anything like that'

'I can't stand for nobody to touch it... my feet when I have it'

'When it flares it's very painful. It causes me not to move it' 
Table 2 Top ranked seven concerns* for African-American and Caucasian women (Continued)

\begin{tabular}{|c|c|c|}
\hline & 'My feet feel tender it makes me walk different. Like I'm hopping' & \\
\hline & $\begin{array}{l}\text { 'Affects my life very very bad... It's sorer than anything else. I } \\
\text { cannot walk. All I can do is hop to the bed' }\end{array}$ & \\
\hline & $\begin{array}{l}\text { 'Sudden sharp pains in legs, thighs, and foot during and between } \\
\text { attacks' }\end{array}$ & \\
\hline & 'I just woke up and couldn't have anything touching me' & \\
\hline \multirow[t]{4}{*}{ Swelling and heat in the area of attack } & 'I have hurting and swelling in my right knee' & 21 \\
\hline & $\begin{array}{l}\text { 'It's in my hands and knee right now they are treating it with } \\
\text { cortisone' }\end{array}$ & \\
\hline & 'Causes swelling' & \\
\hline & 'Affected area is hot' & \\
\hline \multirow[t]{3}{*}{ Constant pain } & 'I am in constant pain' & 15 \\
\hline & 'It never stops hurting' & \\
\hline & 'Even when you don't have a flare up it does not stop hurting' & \\
\hline \multirow[t]{12}{*}{ Problem with daily activities and at-home productivity } & 'Walking long distances - it hurts' & 15 \\
\hline & 'Can't run, period' & \\
\hline & 'Can't get up quickly' & \\
\hline & 'My gout is in my right hand so it hurts when I write' & \\
\hline & $\begin{array}{l}\text { 'I have problems dressing myself because of the problems with } \\
\text { swelling and pain' }\end{array}$ & \\
\hline & 'Affects things that I have to do around the house' & \\
\hline & 'I can't walk when I get an attack' & \\
\hline & 'Can't do a lot of walking' & \\
\hline & $\begin{array}{l}\text { 'Gout 3-4 times a year - and it hurts so bad I can't walk, or stand } \\
\text { for the sheets to even touch it' }\end{array}$ & \\
\hline & $\begin{array}{l}\text { 'Sudden sharp pains in legs, thighs, and foot during and between } \\
\text { attacks' }\end{array}$ & \\
\hline & 'I had to limit my volunteering' & \\
\hline & 'Limits my going out of town' & \\
\hline Stiffness in joints & 'I had stiffness in my right knee' & 11 \\
\hline \multirow[t]{4}{*}{ Problem with shoes/footwear } & $\begin{array}{l}\text { 'Causes me to wear a certain type of shoes... definitely no open } \\
\text { toe shoes' }\end{array}$ & 8 \\
\hline & 'I cannot wear shoes at all when it flares up' & \\
\hline & 'I go to church with house shoes on' & \\
\hline & 'I used to love to wear heels' & \\
\hline Work productivity & 'I had to stop working - due to gout' & 7 \\
\hline \multirow[t]{4}{*}{ Diet changes } & 'The food that I eat will make my gout flare' & 6 \\
\hline & $\begin{array}{l}\text { 'I have to be careful about what I eat even the medications that I } \\
\text { take' }\end{array}$ & \\
\hline & 'Restrictive diet' & \\
\hline & $\begin{array}{l}\text { 'I won't eat anything when I go out somewhere because I am } \\
\text { afraid the food might flare up my gout' }\end{array}$ & \\
\hline Emotional impact & 'I cry a lot because it hurts really badly when I have an attack' & 6 \\
\hline
\end{tabular}


Table 2 Top ranked seven concerns* for African-American and Caucasian women (Continued)

African-American women $(n=7)$

Problem with daily activities and at-home productivity and dependency

Problem with shoes/footwear

Gout flare pain

My ability to sleep

Need for canes and crutches

Eating restrictions

Work productivity

Crippling effect of flares

Joint pain and stiffness
The way it affects my life is it affects my ability to walk around and move around all day. And due to the severity of swelling I'm not allowed to wear shoes'

'I can't go up and down the steps like I would like'

'Can't comb hair'

'It affects me because I can't walk. When it flares up I can't walk at all. I will be in the bed for a while. I can't stand to put your foot on the pillow'

'I could stand there and watch my feet start swelling'

'Swelling of my hands makes it hard to open anything. I have to ask the neighbor for help sometimes. It's hard to lift a skillet or any kind of pot or pan'

'Hard to move and wear shoes on my feet no matter what kind or size. It's like it's hard to lift the shoe. I will be bed ridden can't get up and go

'Had to get support stockings'

'Most of the time I have to be barefoot'

'Mine flares up and I have a lot of pain. I can't wear flat shoes I have to wear a little wedge shoes so that my feet will be going down so I can walk'

Very painful and it makes it hard to drive. Sometimes you can't drive at all'

'When mine flares in my foot I can't even let the sheet touch it'

When I am walking my feet will swell. Then my in-step starts aching like a toothache. It makes me cry. It's like you want to pop the joint, but it won't pop'

'Sharp pain in toe'

'Loss of appetite during a flare. You end up losing weight because of this'

'You're in so much pain you can't eat'

'My ability to walk stand and sleep. I toss from side to side. It keeps me up all the time day and night...especially during flares'

'Need for canes crutches and walkers -you feel so swollen you feel like you don't have any balance. I have fallen all over the place'

'Be choice-y about what I eat. I can't eat beef, red meat and seafood.

'You get tired of eating chicken all the time'

'Can't drink alcohol especially beer'

'Causes problems with work. I had to stop working and I was put on disability.'

'I was constantly on my feet'

'It cripples you'

'Can't get out of the bed for a month'

'Can't get to the bathroom'

'Gout destroyed my finger ligaments'

'I have it all over my body'

'It's in hips legs back of head arms'

'(Aches and pains)... constant - all the time'

'Aches and pains and stiffness and numbness in joints all the time' 'Have to rock to get up' 
Table 2 Top ranked seven concerns* for African-American and Caucasian women (Continued)

\author{
Caucasian women $(n=6)$ \\ Unpredictability of flare that brings a normal day to \\ a halt
}

Work productivity

Dependency

Medication side effects

Modification in physical activity due to gout and to avoid flares

Problem with shoes/footwear

Deformity

Pain interfering with sleep
'Unpredictable and can strike at any time. It ruins any plans. I'm a liability to my family because they never know what to expect'

'Can't make plans to do anything'

When I was having it so much. My daughter would call to ask me to babysit. It's like we both knew I couldn't do it because we didn't know if when the time came I would be able to do it'

'Makes life iffy'

'You never know when it is going to come'

'Just walking though Wal-Mart and then you are limping to get out'

'When the episodes are frequent in the feet I can't make plans because I can't be sure that I will be well'

'When the gout is in the heel, I can't walk at all. So I can't get any work done or go anyplace. When it's in the toe I can walk but with pain difficult doing most things but I can do most'

'I was not able to fix Easter dinner'

'Problem with Walking or exercise of any sort - It is hard to just walk through the house -I live alone and during a flare up I can't even get to the bathroom'

'Activities that you would like to participate in. Ex. You can't walk so you more or less hit the sofa. This for me is exercise'

'It came out in the hand... So I could not write'

'I live alone... (am worried) when am I going to get the next flare up'

'My husband had to do it all'

The medication for gout causes other problems such as diarrhea, itching, difficulty breathing'

'Must be careful the need to take extra caution'

'Must be careful with activities and walking because any misstep, uneven pavement, large gravel can cause insult and precipitate gout'

'If I didn't have gout I could walk like everyone else'

'You end up taking different routes than everyone else'

'Shoes do not fit appropriately because of the foot bump from many attacks'

'I had to change my shoes. I can't wear fancy shoes anymore'

My nail Bed is deformed. I have a deformity.

'It wakes me up. I want to sleep when I go to sleep but it hurts too badly to sleep. Can't touch the sheet or the bed to my foot'

'You'll be sound asleep and the pain will wake you'

'I just put my foot off of the bed'

'You twist the foot to get it in just the right position but nothing works'

*Since some concerns were ranked equally by a group and tied for a rank, some groups have more than seven concerns.

\section{Gender differences in the impact of gout on lives of patients}

All four female nominal groups and only one of the six male nominal groups mentioned problems with shoes. Similarly, two of the four nominal groups in women, but none in men, mentioned joint/limb deformity due to gout. Dependency concerns were mentioned by three of the four nominal groups in women, compared to two of the six nominal groups in men. Sex difficulties due to gout were mentioned in none of the groups in women and four of the six groups in men. 
Race differences in the impact of gout on lives of patients Compared to Caucasians, more African American groups ranked the following among their top seven concerns: (1) dietary restrictions and difficulty with eating certain foods due to gout (red meat, shellfish, seafood, alcohol), $0 / 4$ versus $6 / 6$ groups; (2) severe/extreme pain, $0 / 4$ versus $5 / 6$ groups; (3) gout bringing the day to a 'halt', $0 / 4$ versus $2 / 6$ groups; (4) effect on emotional health/irritability, 1/4 versus $4 / 6$ groups; and (4) the need to use canes/crutches during flares, $0 / 4$ versus $2 / 6$ groups. On the other hand, Caucasian groups were more likely to report the impact of gout on work productivity among their top seven concerns, 3/4 Caucasian groups versus 2/6 African American groups.

\section{Discussion}

This is the first qualitative study to focus on the impact of gout on QOL in African Americans and women with gout, both understudied populations. An elegant previous study in 11 men with gout identified three themes - the lack of knowledge related to gout, the progressiveness of untreated gout and the impact of disease (pain, dependency on family members, isolation, work disability) [26]. The concept covered was broad and diverse and women were not included. Our study builds on this foundation [26] and adds significant knowledge to this area. Other qualitative and quantitative studies have covered an even wider range of gout-related issues including treatment, knowledge, disease monitoring, outcomes and patient and clinician perspective within each study $[24,25,42]$. The emergence of clinical trial and survey data showing QOL deficits in gout patients [18-23] indicates that we need a better understanding of the patient perspective of the impact of gout on their lives.

What does this study tell us that we did not already know? This is the first study to describe differences in QOL by gender and race in patients with gout. Compared to Caucasians, African Americans with gout were somewhat more likely to report dietary restrictions due to gout, associated emotional burden, severe pain during gout flares, the need for canes/crutches during flares and gout bringing their day to a halt. This indicates that the patient experience of gout may differ by race. Gout severity may be higher in African Americans, a hypothesis that needs to be tested in future studies. African Americans have a lower rate of use of urate-lowering drugs compared to Caucasians, which may indicate less optimal disease control in African-Americans with gout [14]. This may lead to higher disease burden and a greater impact on QOL.

Women were more concerned about the difficulty with footwear, dependency and joint deformity, while men were more concerned about interference with sexual activity. These gender differences might reflect different social roles and differing priorities. The somewhat higher mean age of women than men with gout (68 versus 63 years) may also have contributed to these differences. To our knowledge, this is the first study with an adequate number of minorities and women to allow such an analysis. Whether these findings also indicate a difference in disease manifestation by gender needs to be examined in future studies.

Our study highlights a major and profound impact of gout on patients' QOL. Several aspects of impact of gout on patients' lives have not been previously reported, including the effect of gout on sexual function, sleep, hobbies, employability, relationships etc. Patients recognized the impact of gout flares on the desire to have sex as well as problems having sex. Gout patients described sleep disruption, with problems falling asleep and gout flares waking them up. A recent clinical study showing an independent association of gout with sleep problems [43] and a pre-clinical study showing altered rapid eye movement sleep and total sleep time after an intra-articular injection of uric acid [44] are highly supportive. Sleep disturbances are common in rheumatoid arthritis [45,46], another inflammatory arthritis, and respond to treatment with disease-modifying agents that target cytokines [47]. It remains to be seen if effective treatment of gout can reduce sleep problems in gout patients.

Patients described a significant disruption of lifestyle due to gout. Patients experienced gout as a life-changing event leading to the loss of job, and some had to apply for disability. These are major life events and signify that the impact of this disease can be devastating in many patients. Patients also needed crutches and walking aids during acute gout flares and felt that they were aging prematurely. Our study confirmed the impact of gout on patients' lives recognized in the earlier study [26], namely, severe pain, dependency, work disability, dietary restrictions and social isolation. These findings substantiate the disease burden and the broad impact on patients' lives.

What should change in the clinical practice? These findings may not surprise rheumatologists. The impact of gout on patients' lives may not be as apparent to primary care physicians, where most time during outpatient visits is spent discussing and managing other chronic co-existent conditions (for example, heart disease, hypertension), with little time left to assess the impact of gout. Our study indicates that due attention should be paid to gout-related symptoms and associated disability, due both to gout flares as well as chronic gout, given its profound effects on patients' QOL.

What are the implications for research? Low rates of appropriate gout treatment [2,5-10], and considerable suffering attributable to gout [18-23], in conjunction with our study findings, imply that we need effective, novel interventions, to optimize gout management, for example, a nurse-led gout clinic [48]. Very few areas of medicine are as well-suited for rigorous translational research as gout. 
Our findings were consistent with our theoretical model that proposes that an illness impacts a person when the $\mathrm{BBC}$ chain is destabilized. In particular, the themes/domains identified most commonly by the patients mapped to either identity-relevant performances with a loss of self or body failures; the most disruptive to the BBC chain ranked the highest. This finding also supports the utility of this model in a chronic musculoskeletal condition. Several aspects of impact of gout on patients' lives (work productivity, job performance, social life) were similar to, but more severe than those described by Lambert et al. in patients with osteoarthritis [49].

The study findings must be interpreted considering the study strengths and limitations. Our study, purposefully oversampled for African Americans, is representative of patients with gout [50]. Our goal was to study an underserved and understudied population, that is, African Americans with gout. However, the majority of the patients were men, which is representative of this condition. Enough nominal groups were conducted within each strata of race and gender to achieve saturation, with a minor exception of Caucasian women, where only one nominal group could be conducted. This was due to the availability of very few Caucasian women with gout for study screening, which mirrors the epidemiology of gout in the US [1]. Another limitation was that disease characteristics (disease duration, flares, gout medications et cetera) and post-menopausal status were not obtained for the patients. This limits our ability to hypothesize whether the gender differences might be related to menopausal status. The study strengths include a community clinic-based sample; focus on a single question and inclusion of a large number of African Americans and women with gout.

\section{Conclusions}

In conclusion, qualitative research assessing the impact of gout on patients' lives and how this differs by gender and race was conducted. A significant impact of gout on patients' lives above and beyond acute pain and functional limitations with gout flares was evident, including the impact on sexual function, sleep, social life, emotional health, hobbies and footwear. Most concerns expressed by patients mapped to our proposed trajectory model with the $\mathrm{BBC}$ chain. Several differences in the impact of gout on QOL by gender and race were noted. Future studies should explore the potential underlying mechanisms of these patient-identified QOL deficits and design interventions targeting these mechanisms.

The University of Alabama at Birmingham's Institutional Review Board (IRB) approved this study and all investigations were conducted in conformity with ethical principles of research.

\section{Abbreviations}

BBC: body, biographical time and conceptions of self; ICD-9-CM: International Classification of Diseases, ninth revision, common modification code; NGT: nominal group technique; QOL: quality of life; ULT: urate-lowering therapy.

\section{Competing interests}

There are no competing conflicts/interest related to this study. JAS has received research and travel grants from Takeda and Savient, and consultant fees from Savient, Takeda, Regeneron and Allergan.

\section{Authors' contributions}

JAS designed the study, developed the protocol and obtained IRB approval, conducted the nominal sessions, analyzed the voting by the participants and the data, wrote the first draft of the manuscript and revised it and made the decision to submit it. All authors read and approved the final manuscript.

\section{Acknowledgements}

I am thankful to Bridgett Alday, Ana Oliviera and Aseem Bharat for contacting patients and providing support for conducting the nominal groups and Mary Elkins for the administrative oversight. I thank Dr Bruce Lambert for his insightful comments on this paper. I thank several colleagues and patients who provided informal input into drafting the question for the nominal groups. This material is the result of work supported by a grant from the Division of Rheumatology at the University of Alabama at Birmingham and the resources and use of facilities at the Birmingham VA Medical Center, Alabama, USA. JAS is also supported by grants from the Agency for Health Quality and Research Center for Education and Research on Therapeutics (AHRQ CERTs) U19 HS021110, National Institute of Arthritis, Musculoskeletal and Skin Diseases (NIAMS) P50 AR060772 and U34 AR062891, National Institute of Aging (NIA) U01 AG018947, National Cancer Institute (NCI) U10 CA149950, and research contract CE-1304-6631 from Patient Centered Outcomes Research Institute (PCORI).

\section{Author details}

${ }^{1}$ Medicine Service, Birmingham VA Medical Center, Birmingham, AL, UK. ${ }^{2}$ Department of Medicine at School of Medicine and Division of Epidemiology at School of Public Health, University of Alabama, Faculty Office Tower 805B, 510 20th Street S, Birmingham, AL 35294, UK. ${ }^{3}$ Department of Orthopedic Surgery, Mayo Clinic College of Medicine, Rochester, MN, USA.

Received: 17 February 2014 Accepted: 29 May 2014

Published: 24 June 2014

\section{References}

1. Zhu Y, Pandya BJ, Choi HK: Prevalence of gout and hyperuricemia in the US general population: the National Health and Nutrition Examination Survey 2007-2008. Arthritis Rheum 2011, 63:3136-3141.

2. Singh JA, Hodges JS, Toscano JP, Asch SM: Quality of care for gout in the US needs improvement. Arthritis Rheum 2007, 57:822-829.

3. Garg R, Sayles HR, Yu F, Michaud K, Singh J, Saag KG, Mikuls TR: Gout-related health care utilization in US emergency departments, 2006 through 2008. Arthritis Care Res (Hoboken) 2013, 65:571-577. Epub 2012/09/06.

4. Wertheimer Al, Morlock R, Becker MA: A Revised Estimate of the Burden of Illness of Gout. Curr Ther Res 2013, 75:1-4.

5. Singh JA, Hodges JS, Asch SM: Opportunities for improving medication use and monitoring in gout. Ann Rheum Dis 2009, 68:1265-1270.

6. Harrold LR, Andrade SE, Briesacher BA, Raebel MA, Fouayzi H, Yood RA, Ockene IS: Adherence with urate-lowering therapies for the treatment of gout. Arthritis Res Ther 2009, 11:R46.

7. Harrold LR, Yood RA, Mikuls TR, Andrade SE, Davis J, Fuller J, Chan KA, Roblin D, Raebel MA, Von Worley A, Platt R, Saag KG: Sex differences in gout epidemiology: evaluation and treatment. Ann Rheum Dis 2006, 65:1368-1372.

8. Mikuls TR, Farrar JT, Bilker WB, Fernandes S, Saag KG: Suboptimal physician adherence to quality indicators for the management of gout and asymptomatic hyperuricaemia: results from the UK General Practice Research Database (GPRD). Rheumatology (Oxford) 2005, 44:1038-1042. 
9. Sarawate CA, Brewer KK, Yang W, Patel PA, Schumacher HR, Saag KG, Bakst AW: Gout medication treatment patterns and adherence to standards of care from a managed care perspective. Mayo Clin Proc 2006, 81:925-934.

10. Sarawate CA, Patel PA, Schumacher HR, Yang W, Brewer KK, Bakst AW: Serum urate levels and gout flares: analysis from managed care data. J Clin Rheumatol 2006, 12:61-65.

11. Khanna D, Fitzgerald JD, Khanna PP, Bae S, Singh MK, Neogi T, Pillinger MH, Merill J, Lee S, Prakash S, Kaldas M, Gogia M, Perez-Ruiz F, Taylor W, Liote F, Choi H, Singh JA, Dalbeth N, Kaplan S, Niyyar V, Jones D, Yarows SA, Roessler B, Kerr G King C, Levy G, Furst DE, Edwards NL, Mandell B, Schumacher HR, Robbins M, Wenger N, Terkeltaub R: American College of Rheumatology guidelines for management of gout. Part 1: systematic nonpharmacologic and pharmacologic therapeutic approaches to hyperuricemia. Arthritis Care Res (Hoboken) 2012 2012, 64:1431-1446.

12. Zhang W, Doherty M, Bardin T, Pascual E, Barskova V, Conaghan P, Gerster J, Jacobs J, Leeb B, Liote F, McCarthy G, Netter P, Nuki G, Perez-Ruiz F, Pignone A, Pimentao J, Punzi L, Roddy E, Uhlig T, Zimmermann-Gorska I: EULAR evidence based recommendations for gout. Part II: Management. Report of a task force of the EULAR Standing Committee for International Clinical Studies Including Therapeutics (ESCISIT). Ann Rheum Dis 2006, 65:1312-1324.

13. Singh JA: Racial and gender disparities among patients with gout. Curr Rheumatol Rep 2013, 15:307.

14. Krishnan $\mathrm{E}$, Lienesch $\mathrm{D}$, Kwoh CK: Gout in ambulatory care settings in the United States. J Rheumatol 2008, 35:498-501.

15. Solomon DH, Avorn J, Levin R, Brookhart MA: Uric acid lowering therapy: prescribing patterns in a large cohort of older adults. Ann Rheum Dis 2008, 67:609-613.

16. Harris CM, Lloyd DC, Lewis J: The prevalence and prophylaxis of gout in England. J Clin Epidemiol 1995, 48:1153-1158.

17. Dalbeth N, Petrie KJ, House M, Chong J, Leung W, Chegudi R, Horne A, Gamble G, McQueen FM, Taylor WJ: Illness perceptions in patients with gout and the relationship with progression of musculoskeletal disability. Arthritis Care Res (Hoboken) 2011, 63:1605-1612.

18. Khanna PP, Nuki G, Bardin T, Tausche AK, Forsythe A, Goren A, Vietri J, Khanna D: Tophi and frequent gout flares are associated with impairments to quality of life, productivity, and increased healthcare resource use: Results from a cross-sectional survey. Health Qual Life Outcomes 2012, 10:117.

19. Lee SJ, Hirsch JD, Terkeltaub R, Khanna D, Singh JA, Sarkin A, Kavanaugh A Perceptions of disease and health-related quality of life among patients with gout. Rheumatology (Oxford) 2009, 48:582-586.

20. Roddy E, Zhang W, Doherty M: Is gout associated with reduced quality of life? A case-control study. Rheumatology (Oxford) 2007, 46:1441-1444.

21. Singh JA, Strand V: Gout is associated with more comorbidities, poorer health-related quality of life and higher healthcare utilisation in US veterans. Ann Rheum Dis 2008, 67:1310-1316.

22. Khanna PP, Perez-Ruiz F, Maranian P, Khanna D: Long-term therapy for chronic gout results in clinically important improvements in the healthrelated quality of life: short form-36 is responsive to change in chronic gout. Rheumatology (Oxford) 2011, 50:740-745.

23. Sundy JS, Baraf HS, Yood RA, Edwards NL, Gutierrez-Urena SR, Treadwell EL, Vazquez-Mellado J, White WB, Lipsky PE, Horowitz Z, Huang W, Maroli AN, Waltrip RW 2nd, Hamburger SA, Becker MA: Efficacy and tolerability of pegloticase for the treatment of chronic gout in patients refractory to conventional treatment: two randomized controlled trials. JAMA 2011, 306:711-720.

24. Harrold LR, Mazor KM, Velten S, Ockene IS, Yood RA: Patients and providers view gout differently: a qualitative study. Chronic IIIn 2010, 6:263-271.

25. Spencer K, Carr A, Doherty M: Patient and provider barriers to effective management of gout in general practice: a qualitative study. Ann Rheum Dis 2012, 71:1490-1495.

26. Lindsay K, Gow P, Vanderpyl J, Logo P, Dalbeth N: The experience and impact of living with gout: a study of men with chronic gout using a qualitative grounded theory approach. J Clin Rheumatol 2011, 17:1-6.

27. Helmick CG, Felson DT, Lawrence RC, Gabriel S, Hirsch R, Kwoh CK, Liang MH, Kremers HM, Mayes MD, Merkel PA, Pillemer SR, Reveille JD, Stone JH: Estimates of the prevalence of arthritis and other rheumatic conditions in the United States. Part I Arthritis Rheum 2008, 58:15-25.

28. Corbin J, Strauss AL: Accompaniments of chronic illness: changes in body, self, biography, and biographical time. In Research in the Sociology of Health Care: A Research Annual. Vol. 6. The Experience and Management of
Chronic IIIness Greenwich, Vol. 6. Edited by Roth JA, Conrad P. Greenwich, CT: JAI Press, Inc; 1987:249-281.

29. Corbin JM, Strauss AL: Experiencing body failure and a disrupted self image. In Unending Work and Care: Managing Chronic Illness at Home. Edited by Corbin J, Strauss AL. San Francisco, Calif: Jossey-Bass; 1988:49-67.

30. Lambert BL, Street RL, Cegala DJ, Smith H, Kurtz S, Schofield T: Providerpatient communication, patient-centered care, and the mangle of practice. Health Commun 1997, 9:27-43.

31. Charmaz K: Loss of self: a fundamental form of suffering in the chronically ill. Sociol Health IIIn 1987, 5:168-195.

32. Gallagher M, Hares T, Spencer J, Bradshaw C, Webb I: The nominal group technique: a research tool for general practice? Fam Pract 1993, 10:76-81.

33. Miller D, Shewchuk R, Elliot TR, Richards S: Nominal group technique: a process for identifying diabetes self-care issues among patients and caregivers. Diabetes Educ 2000, 26:305-310. 312, 314

34. Jefferson WK, Zunker C, Feucht JC, Fitzpatrick SL, Greene LF, Shewchuk RM, Baskin ML, Walton NW, Phillips B, Ard JD: Use of the Nominal Group Technique (NGT) to understand the perceptions of the healthiness of foods associated with African Americans. Eval Program Plann 2010, 33:343-348.

35. Kleiner-Fisman G, Gryfe P, Naglie G: A Patient-Based Needs Assessment for Living Well with Parkinson Disease: Implementation via Nominal Group Technique. Park Dis 2013, 2013:974964.

36. MacLachlan M: Identifying problems in community health promotion: an illustration of the Nominal Group Technique in AIDS education. J R Soc Health 1996, 116:143-148.

37. Pastrana $T$, Radbruch $L$, Nauck F, Hover G, Fegg M, Pestinger M, Ross J, Krumm N, Ostgathe C: Outcome indicators in palliative care-how to assess quality and success, Focus group and nominal group technique in Germany. Support Care Cancer 2010, 18:859-868.

38. Pena A, Estrada CA, Soniat D, Taylor B, Burton M: Nominal group technique: a brainstorming tool for identifying areas to improve pain management in hospitalized patients. J Hosp Med 2012, 7:416-420

39. Redman S, Carrick S, Cockburn J, Hirst S: Consulting about priorities for the NHMRC National Breast Cancer Centre: how good is the nominal group technique. Aust N Z J Public Health 1997, 21:250-256.

40. Singh JA: Challenges faced by patients in gout treatment: a qualitative study. J Clin Rheumatol 2014, 20(3):172-174.

41. Singh JA: Research priorities in gout: the patient perspective. J Rheumatol 2014, 41(3):615-616.

42. Harrold LR, Mazor KM, Peterson D, Naz N, Firneno C, Yood R: Patients' knowledge and beliefs concerning gout and its treatment: a population based study. BMC Musculoskelet Disord 2012, 13:180.

43. Covarrubias-Gomez A, Guevara-Lopez U, Haro-Valencia R, Alvarado-Suarez $\mathrm{M}$ : Importance of the obstructive sleep apnea disorder for perioperative medicine. Rev Med Inst Mex Seguro Soc 2007, 45:371-380.

44. Guevara-Lopez U, Ayala-Guerrero F, Covarrubias-Gomez A, Lopez-Munoz FJ, Torres-Gonzalez R: Effect of acute gouty arthritis on sleep patterns: a preclinical study. Eur J Pain 2009, 13:146-153.

45. Westhovens R, Van der Elst K, Matthys A, Tran M, Gilloteau I: Sleep problems in patients with rheumatoid arthritis. J Rheumatol 2014, 41:31-40. Epub 2013/12/03

46. Abbasi M, Yazdi Z, Rezaie N: Sleep disturbances in patients with rheumatoid arthritis. Niger J Med 2013, 22:181-186

47. Fragiadaki K, Tektonidou MG, Konsta M, Chrousos GP, Sfikakis PP: Sleep disturbances and interleukin 6 receptor inhibition in rheumatoid arthritis. J Rheumatol 2012, 39:60-62.

48. Rees F, Jenkins W, Doherty M: Patients with gout adhere to curative treatment if informed appropriately: proof-of-concept observational study. Ann Rheum Dis 2013, 72:826-830.

49. Lambert BL, Butin DN, Moran D, Zhao SZ, Carr BC, Chen C, Kizis FJ: Arthritis care: comparison of physicians' and patients' views. Semin Arthritis Rheum 2000, 30:100-110.

50. Wells AF, MacDonald PA, Chefo S, Jackson RL: African American patients with gout: efficacy and safety of febuxostat vs allopurinol. BMC Musculoskelet Disord 2012, 13:15.

doi:10.1186/ar4589

Cite this article as: Singh: The impact of gout on patient's lives: a study of African-American and Caucasian men and women with gout. Arthritis Research \& Therapy 2014 16:R132. 